\title{
Chewing simulation of zirconia implant supported restorations
}

\author{
Rohr, Nadja ; Balmer, Marc ; Müller, Johannes A ; Märtin, Sabrina ; Fischer, Jens
}

\begin{abstract}
PURPOSE To test three potential prosthetic material options for zirconia implants in regard to their mechanical properties, loading and retention capacity as well as to record abrasion after chewing simulation followed by thermocyclic aging. METHODS Molar crowns $(\mathrm{n}=96)$ of three different computeraided design/computer-aided manufacturing (CAD/CAM) materials were produced and cemented on zirconia implants (ceramic.implant, Vita) with a diameter of $4.5 \mathrm{~mm}$. Monolithic zirconia (Vita YZ [YZ] with RelyX Unicem 2 Automix [RUN], polymer-infiltrated ceramic (Vita Enamic [VE]) with Vita Adiva F-Cem [VAF] and acrylate polymer (CAD Temp [CT]) with RelyX Ultimate [RUL]. Fracture load and retentive force of the crowns were measured after $24 \mathrm{~h}$ water storage at $37{ }^{\circ} \mathrm{C}$ and after a chewing simulation followed by thermocyclic aging. Abrasion was recorded by matching stereolithography-data of the crowns obtained before and after chewing simulation. Additionally, the mechanical properties and bonding capabilities of the crown and cement materials were assessed. RESULTS Fracture load values were significantly highest for $\mathrm{YZ}>\mathrm{VE}=\mathrm{CT}$. Retention force values did not differ significantly between the materials. The aging procedure did not affect the fracture load values nor the retention force significantly. Abrasion depth of the crowns was lowest for YZ followed by VE and CT. On unpolished crowns, abrasion of YZ and VE tended to be higher than on polished specimens. CONCLUSIONS Based on the obtained in-vitro results, all tested materials can be recommended for the use on zirconia implants, although CT is only approved for temporary crowns. The loading and retention capacity of the materials were not significantly affected by aging.
\end{abstract}

DOI: https://doi.org/10.1016/j.jpor.2019.02.002

Posted at the Zurich Open Repository and Archive, University of Zurich

ZORA URL: https://doi.org/10.5167/uzh-170504

Journal Article

Accepted Version

\section{(cc) $(9) \Theta \Theta$}

The following work is licensed under a Creative Commons: Attribution-NonCommercial-NoDerivatives 4.0 International (CC BY-NC-ND 4.0) License.

Originally published at:

Rohr, Nadja; Balmer, Marc; Müller, Johannes A; Märtin, Sabrina; Fischer, Jens (2019). Chewing simulation of zirconia implant supported restorations. Journal of Prosthodontic Research, 63(3):361-367.

DOI: https://doi.org/10.1016/j.jpor.2019.02.002 
ORIGINAL RESEARCH

\section{Chewing simulation of zirconia implant supported restorations}

Nadja Rohr ${ }^{1}$, Marc Balmer ${ }^{2}$, Johannes A. Müller ${ }^{1}$, Sabrina Märtin ${ }^{3}$, Jens Fischer ${ }^{1,3}$

${ }^{1}$ Division of Dental Materials and Engineering, Department of Reconstructive Dentistry, University Center for Dental Medicine, University of Basel, Basel, Switzerland

${ }^{2}$ Clinic of Fixed and Removable Prosthodontics and Dental Material Science, Center of Dental Medicine, University of Zurich, Zurich, Switzerland

${ }^{3}$ Vita Zahnfabrik, Bad Säckingen, Germany

Correspondence:

Nadja Rohr, Division of Dental Materials and Engineering, Department of Reconstructive Dentistry, University Center for Dental Medicine, University of Basel, Hebelstrasse $3, \mathrm{CH}-$ 4056 Basel, Switzerland

EMail: nadja.rohr@unibas.ch

phone: +41612672629

KEYWORDS: zirconia implant, chewing simulation, fracture load, retentive force, abrasion

Number of text pages: 5.5

Number of tables: 4

Number of figures: 4 


\section{ACKNOWLEDGEMENTS AND CONFLICT OF INTEREST}

The authors would like to thank Vita Zahnfabrik, Bad Säckingen for providing this study with materials. We are also grateful to Fredy Schmidli, University Center of Dental Medicine Basel, Switzerland for the lab assistance.

$\mathrm{JF}$ is - beside his function as Head of Division of Dental Materials and Engineering at the University of Basel, Switzerland - Manager Research \& Development at VITA Zahnfabrik, Bad Säckingen, Germany. SM is Clinical Affairs Manager at VITA Zahnfabrik. All other authors report no conflict of interest. 


\section{Chewing simulation of zirconia implant supported restorations}

\section{ABSTRACT}

Purpose: To test three potential prosthetic material options for zirconia implants in regard to their mechanical properties, loading and retention capacity as well as to record abrasion after chewing simulation followed by thermocyclic aging.

Methods: Molar crowns $(n=96)$ of three different CAD/CAM materials were produced and cemented on zirconia implants (ceramic.implant, Vita) with a diameter of $4.5 \mathrm{~mm}$. Monolithic zirconia (Vita YZ [YZ] with RelyX Unicem 2 Automix [RUN], polymerinfiltrated ceramic (Vita Enamic [VE]) with Vita Adiva F-Cem [VAF] and acrylate polymer (CAD Temp [CT]) with RelyX Ultimate [RUL]. Fracture load and retentive force of the crowns were measured after $24 \mathrm{~h}$ water storage at $37^{\circ} \mathrm{C}$ and after a chewing simulation followed by thermocyclic aging. Abrasion was recorded by matching stereolithography-data of the crowns obtained before and after chewing simulation. Additionally, the mechanical properties and bonding capabilities of the crown and cement materials were assessed.

Results: Fracture load values were significantly highest for $Y Z>V E=C T$. Retention force values did not differ significantly between the materials. The aging procedure did not affect the fracture load values nor the retention force significantly. Abrasion depth of the crowns was lowest for YZ followed by VE and CT. On unpolished crowns, abrasion of $Y Z$ and VE tended to be higher than on polished specimens.

Conclusions: Based on the obtained in-vitro results, all tested materials can be recommended for the use on zirconia implants, although CT is only approved for temporary crowns. The loading and retention capacity of the materials were not significantly affected by aging. 


\section{INTRODUCTION}

Zirconia dental implants can be considered a promising alternative to the wellestablished titanium implants [1-6]. The elastic modulus of zirconia with $210 \mathrm{GPa}$ [7] is however twice the one of titanium [8]. Therefore, the transmission of intraoral forces from the suprastructure to the implant and to the surrounding bone is different. As a consequence, for zirconia implants restored with veneered zirconia crowns in clinical studies, unacceptable rates of veneer chipping of up to $47 \%$ after up to 5 years have been reported [2,4,5,9], indicating stresses that were higher than the strength of the veneering ceramic itself or the bond strength between veneering ceramic and framework. It may be concluded that veneered zirconia is not suitable to restore zirconia implants.

To avoid the need of veneering, monolithic restorations might be considered. In laboratory studies, monolithic zirconia displayed a high fracture resistance irrespective of the cement applied $[10,11]$. This finding is supported for zirconia crowns on titanium [12], steel [13] and composite resin bases [14]. However, in this case the complete system composed of zirconia implant and zirconia restoration is rigid and the effect of stress distribution in the periimplant bone is unknown.

Another restorative approach for zirconia implants might be the use of a more elastic crown material to compensate for the high stiffness of the implant material. Compared to zirconia, lithium disilicate has a lower modulus of elasticity of $67 \mathrm{GPa}$ [15]. For 22 monolithic crowns on zirconia implants a Kaplan-Meier success estimate of only $91,7 \%$ after 5 years was reported [16]. The incidence of significantly increasing occlusal roughness over time as reported may indicate an unfavorable stress distribution in the crown and questions the suitability of this material in a monolithic state for clinical application on zirconia implants in the premolar or molar region. 
Further, laboratory results testing specific monolithic solutions for the prosthetic treatment of zirconia implants with more elastic materials such as polymer, composite or polymer-infiltrated ceramic are available $[10,11,17]$. The in-vitro fracture load of polymer-infiltrated ceramic on zirconia implants has been rated sufficient to withstand loads in the molar region if the restoration is fixed with an adhesive cement with a high compressive strength that is able to increase the loading capacity of the system $[10,17]$.

Due to differences in test set-ups, the retrieved fracture load [10-14,17-20] or retention force $[21,22]$ values can vary greatly for the respective materials. Parameters such as crown design, core material, preparation form, loading angle as well as cementation procedures influence the obtained values.

The effect of aging in the intraoral environment is simulated by subjecting the specimens to procedures such as dynamic loading and/or thermocyclic aging $[12,18,19-21,23,24]$. However, in most studies only fracture load or retentive force values of the whole system are measured and the components by themselves are not properly characterized, which leads to a lack of data to interpret the obtained results. The purpose of the present study was therefore to test three potential prosthetic treatment options for zirconia implants in regard to their mechanical properties, loading and retention capacity as well as to record abrasion after chewing simulation followed by thermocyclic aging.

\section{MATERIALS AND METHODS}

Three different restorative treatment options for a one-piece (monotype) zirconia implant were tested in regard to their loading and retention capacity as well as the respective materials mechanical and bonding properties and how they are affected by aging. The chosen materials were monolithic zirconia (Vita YZ T [YZ] with self- 
adhesive cement (RelyX Unicem 2 Automix [RUN]) for a simple handling, polymerinfiltrated ceramic (Vita Enamic [VE]) with an adhesive cement (Vita Adiva F-Cem [VAF]) with a high compressive strength [10] to sufficiently support the material and an acrylate polymer (CAD Temp [CT]) with an adhesive resin cement (RelyX Ultimate [RUL]) that is able to bond to the polymer via a universal primer [25] (Table 1). An overview of the tested parameters is given in Fig. 1.

\subsection{Loading and retention capacity of the restorative system}

Ninety-six zirconia implants (ceramic.implant, vitaclinical, Bad Säckingen, Germany) with a diameter of $4.5 \mathrm{~mm}$ and a length of $10 \mathrm{~mm}$ in the endosseous part were embedded with a $3 \mathrm{~mm}$ clearance between implant neck and resin surface according to ISO 14801:2008 in epoxy (RenCast CW 20/Ren HY 49, Huntsman Advanced Materials, Duxford, UK).

One implant was scanned with an optical scanner (Omnicam, Sirona, Bensheim, Germany). A standardized molar crown (position 46) was designed by CAD-software (inLab SW3.88, Sirona) and milled (inLab MCXL, Sirona).

Thirty-two crowns of a zirconia (Vita YZ T, Vita Zahnfabrik, Bad Säckingen), 32 crowns of a polymer-infiltrated ceramic (Vita Enamic, Vita) and 32 crowns of an acrylate polymer (Vita CAD-Temp, Vita) were produced following the manufacturer's recommendations. The occlusal surfaces of 16 crowns from each material for the fracture load test were polished with ceramic polishers and finalized by goat hair buffing wheel and polishing paste (Wetzler Dental, Bielefeld, Germany). Polished and unpolished crowns were used to evaluate the effect of the surface finish on abrasion. All crowns were cemented on the zirconia implants according to the pretreatments provided in Table 2 for the respective material combination according to the manufacturers recommendations. The crowns were filled with cement, placed on the 
implants and loaded with $25 \mathrm{~N}$ for $10 \mathrm{~min}$ at room temperature using a custom-made device. Light-curing was applied afterwards for 60s per crown (20s from occlusal, buccal and oral site) (Elipar DeepCure-S, 3M Espe, Neuss, Germany). The specimens were then stored in $37^{\circ} \mathrm{C}$ distilled water for $24 \mathrm{~h}$ (CTS T-4025, Hechingen, Germany).

Eight of the polished specimens of each material were then subjected to a fracture load test using a universal testing machine (Zwick Z020, Zwick/Roell, Ulm, Germany). A steel ball (4.5mm diameter) was adjusted in the center of the occlusal surface with a $0.2 \mathrm{~mm}$ thick tin foil (Dentaurum, Pforzheim, Germany) placed between the ball and the occlusal surface to attain a homogenous stress distribution. Fracture load testing was performed at a cross-head speed of $1 \mathrm{~mm} / \mathrm{min}$ and the fracture load values were recorded (testXpert V 2.2, Zwick/Roell).

Eight of the unpolished specimens of each material were subjected to a crown retention test. The crowns were removed at a crosshead speed of $1 \mathrm{~mm} / \mathrm{min}$ (Zwick Z020, Zwick/Roell) in a custom specimen holder from the implants parallel to the implant axis and retention force was recorded (textXpert v2.2; Zwick/Roell).

The other 16 specimens of each material were subjected to aging followed by either the fracture load test of the 8 polished specimens or retention test of the 8 unpolished specimens as described above. For the aging simulation, the crowns were first placed in a chewing simulator (CS-4.8, SD Mechatronik, Feldkirchen, Germany) and subjected to 1.2 Mio cycles $[20,23,24,26,27]$ with a frequency of $1.5 \mathrm{~Hz}$ (maximal capacity of the chewing simulator) and a force of $49 \mathrm{~N}$ to initiate subcritical crack growth $[20,26-28]$. Steel balls with a diameter of $4.5 \mathrm{~mm}$ served as antagonists. The specimen chambers were filled with $37^{\circ} \mathrm{C}$ water. Afterwards, the specimens were subjected to $20^{\prime} 000$ thermal cycles of 5 and $55^{\circ} \mathrm{C}$ with a dwell time of $30 \mathrm{~s}$ (THE1100, Mechatronik). Fracture origins and abrasion of unpolished specimens were 
visualized after mechanical testing using light (Wild M7A, Leica, Heerbrugg, Switzerland) and scanning electron microscopy (Philips XL30 FEG ESEM, Philips Electron Optics, Eindhoven, the Netherlands).

\subsection{Abrasion}

The occlusal surface of each crown was scanned before and after aging (Cerec Omnicam, Sirona, Bensheim, Germany). Stereolithography (STL) data was exported and matched using the OraCheck software (V2.10.6044, Cyfex, Zurich, Switzerland). The diameter of the implant served as reference for the software calibration. The abrasion volumes as well as maximum abrasion depth (mean of maximum $10 \%$ deviations) for each specimen were calculated.

\subsection{Mechanical properties of restorative materials}

Mechanical properties as stated below were measured for the restorative materials $\mathrm{YZ}, \mathrm{VE}$ and $\mathrm{CT}$ after $24 \mathrm{~h}$ water storage at $37^{\circ} \mathrm{C}$ (baseline) as well as after aging, meaning storage in water of $37^{\circ} \mathrm{C}$ for $24 \mathrm{~h}$, followed by $20^{\prime} 000$ thermal cycles (THE1100, SD Mechatronik).

\subsubsection{Flexural strength}

Flexural strength of the restorative materials $Y Z, V E$ and $C T$ was measured using the 3-point bending test. Bending bars of $Y Z$ and $V E$ with a dimension of 1.2x4.0x20.0mm (ISO 6872: 2015) and of CT with a dimension of $2.0 \times 2.0 \times 25.0 \mathrm{~mm}$ (ISO 4049: 2018) were produced out of CAD/CAM blocs ( $n=10$ per group). Specimens of VE and CT were manually grinded with silica paper (P1200) to the final dimensions. YZ specimens were cut over dimensioned, grinded (D91; FSM 480 A, Knuth, Wasbek, Germany) and sintered according to the manufacturers' 
recommendations (Zyrcomat, Vita). Edges of the ceramic specimens were chamfered according to ISO 6872. Three-point bending test was performed at a crosshead speed of $0.5 \mathrm{~mm} / \mathrm{min}$ until fracture (Z020, Zwick/Roell). The roller span for $\mathrm{YZ}$ and VE was $12 \mathrm{~mm}$, for CT $20 \mathrm{~mm}$. Flexural strength $\sigma$ was calculated using the following formula:

$\sigma=3 F I / 2 w h^{2}$

$\mathrm{F}$ is the fracture load; I is the roller span; $\mathrm{w}$ is the width and $\mathrm{h}$ is the height of the bar.

\subsubsection{Fracture toughness}

Fracture toughness was measured according to ISO 24370:2005. Five bending bars per group with a dimension of $4.0 \times 3.0 \times 45.0 \mathrm{~mm}$ were produced as described above. Cutting of the notch followed the recommendations of the standard. Depth of the notch was recorded with light microscopy for each specimen separately after the test to vary between 0.72 and $0.88 \mathrm{~mm}$ (i.e. $0.8 \pm 0.08 \mathrm{~mm}$ ). Specimens were loaded until fracture (Z010, Zwick/Roell) at a crosshead speed of $0.5 \mathrm{~mm} / \mathrm{min}$. Fracture toughness KIC was calculated according to ISO $24370: 2005$ using the following formula:

$\mathrm{K}_{\mathrm{IC}}=\mathrm{Y}^{*}{ }_{\min }\left[\mathrm{F}\left(\mathrm{S}_{0}-\mathrm{S}_{\mathrm{i}}\right) / \mathrm{BW}^{3 / 2}\right]$

$Y^{*}{ }_{\min }=\left(3.08+5.00 \alpha_{0}+8.33 \alpha_{0}^{2}\right)\left[1+0.007\left(S_{i} S_{0} / W^{2}\right)^{1 / 2}\right]\left[\left(\alpha_{1}-\alpha_{0}\right) /\left(1-\alpha_{0}\right)\right]$

$F$ is the fracture load; $S_{0}$ is the outer span; $S_{i}$ is the inner span; $B$ is the test specimen thickness; $W$ is the test specimen width; $Y^{*}{ }_{\min }$ is the stress intensity factor coefficient; $a_{0}$ is $a_{0} / W ; a_{1}$ is $a_{1} / W ; a_{0}$ is the chevron tip dimension; $a_{1}$ is the mean chevron dimension.

\subsubsection{Hardness}


Vickers and Martens hardness were determined on flexural strength specimens of all materials with a universal testing machine (ZHU 2.5, Zwick/Roell, Ulm, Germany), using a Vickers indenter. A load of $9.8 \mathrm{~N}$ with a dwell time of $15 \mathrm{~s}$ was applied.

\subsection{Compressive strength of cement materials}

Compressive strength was measured for the cement materials RUN, VAF and RUL after $24 \mathrm{~h}$ water storage at $37^{\circ} \mathrm{C}$ (baseline) as well as after subjecting the specimens to an aging procedure with water storage at $37^{\circ} \mathrm{C}$ for $24 \mathrm{~h}$ followed by $20^{\prime} 000$ thermal cycles (THE-1100, Mechatronik). Cylindrical test specimens $3 \mathrm{~mm}$ in height and diameter of RUN, VAF and RUL ( $n=10$ per group) were produced as described for the indirect tensile strength test. Specimens were loaded axially until fracture at a cross-head speed of $1 \mathrm{~mm} / \mathrm{min}$ (Z020, Zwick/Roell) and compressive strength was calculated using the following formula:

$\sigma_{\mathrm{c}}=\mathrm{F} / \pi(\mathrm{d} / 2)^{2}$

$F$ is the fracture load; $d$ the specimen diameter and $h$ the specimen height

\subsection{Bonding properties}

Shear bond strength was measured between the restorative materials and the cements (YZ/RUN, VE/VAF, CT/RUL) as well as between the implant material and the cements (Impl/RUN, Impl/VAF, Impl/RUL) at baseline (24h water storage at $37^{\circ} \mathrm{C}$ ) and after aging (24h water storage $37^{\circ} \mathrm{C}, 20^{\prime} 000$ thermo cycles). Twelve substrates per group were cut to a dimension of $14 \times 12 \times 3 \mathrm{~mm}$ and pre-treated as it was done for the cementation of the crowns (Table 2). The zirconia substrate of the implant was provided by the manufacturer in the required dimension and with a surface similar to the abutment surface. An acrylic cylinder (D+R Tec, Birmensdorf, Switzerland) with an inner diameter of $2.9 \mathrm{~mm}$ was fastened vertically on the 
pretreated substrate, cement was applied through the opening of the cylinder, compressed with a headless steel screw with a force of $1 \mathrm{~N}$ and light-cured for $60 \mathrm{~s}$ (Elipar DeepCure S, 3M Espe). Shear bond strength test was performed at a crosshead speed of $1 \mathrm{~mm} / \mathrm{min}$ using a universal testing machine (Z020, Zwick/Roell).

\subsection{Statistics}

Data was tested for normal distribution. Logarithmic transformation was applied for data of shear bond strength test due to the variations in standard deviations. Statistical analysis was performed using two-way ANOVA to check for the effect of the applied material and aging protocol $(p<0.05)$. For the abrasion data the effect of the material and surface finish was tested. Post-hoc test Fisher LSD was applied afterwards to determine differences within the subgroups.

\section{RESULTS}

No damage besides the abrasion was detected on all crowns after the aging procedures. Mean and standard deviations of the loading and retention capacity of the restorative system before and after aging are displayed in Fig. 2. For the fracture load, two-way ANOVA revealed a significant effect of the material applied $(p<0.001)$ but no effect of the aging protocol $(p=0.311)$. Within the factor material post-hoc Fisher LSD test displayed that fracture load values of $Y Z$ were significantly higher than those of VE and CT $(p<0.001)$. While performing the fracture load test of $Y Z$, three of the implants in each group, baseline and aging, fractured through the upper endosseous part at a mean force of $3003 \pm 1212 \mathrm{~N}$. The values of the fractured implants were not included into Fig. 2 and the statistical analysis for $\mathrm{YZ}$ crowns. At maximum load, the crowns of all materials fractured into 2-6 pieces. Fracture was 
observed by light and scanning electron microscope to mainly initiate from the occlusal loading point (Fig. 3). For VE and CT, the cement remained on the restorative material fragments after fracture. For $\mathrm{YZ}$ crowns the cement was sticking to both, implant and crown.

For the retention force no effect of either material $(p=0.168)$ or aging protocol $(p=0.649)$ was observed (Fig. 2). No visible damage was detected on the crowns of $\mathrm{YZ}$ and CT from the retention test. On $4 \mathrm{VE}$ crowns within each group, minor chipping fractures $<2 \mathrm{~mm}$ were observed at the cervical part of the crowns. The cement used for VE/VAF and CT/RUL remained inside the crown after removal. The cement RUN that was applied for $\mathrm{YZ}$ broke; the upper half remained inside the crown while the cervical part up to the middle of the abutment remained on the implant, but was easy to remove.

A randomly selected example for the observed abrasion on each material by matching STL-data from before and after aging (chewing simulation and thermal cycling) is displayed in Fig. 4.

The abrasion volumes and the abrasion depths are displayed in Table 3. For the interpretation of the abrasion volume it has to be considered that for $\mathrm{YZ}$ and especially for VE not only abrasions but also build-ups around the abrasion were observed that were automatically subtracted from the abrasion volume. Therefore, the abrasion depth was additionally evaluated. The abrasion depth was significantly affected by the material $(p<0.001)$ and was significantly highest for $C T>V E>Y Z$. For unpolished specimens of $\mathrm{VE}$ and $\mathrm{YZ}$, abrasion tended to be higher than for polished specimens. The means of the abrasive volume correlated linearly to the abrasion depth $\left(y=0.001 x, R^{2}=0.984\right)$.

The results for the mechanical properties of restorative and cement materials as well as the bonding properties are presented with the statistics in Table 4. 


\section{DISCUSSION}

In the present study three potential prosthetic treatment options for zirconia implants were tested in regard to their mechanical properties, loading and retention capacity as well as abrasion after chewing simulation followed by thermocyclic aging.

The obtained fracture load values for all tested material combinations were higher than the maximum chewing forces in the molar region that are reported to vary between $600 \mathrm{~N}$ and 1200N $[29,30]$. Physiological chewing forces are however lower and range within $110 \mathrm{~N}$ to $125 \mathrm{~N}$ in the molar region [31]. Fracture loads were of course highest for $Y Z$ due to the materials' high flexural strength and fracture toughness. For three specimens of each $Y Z$ group, the loading capacity of the $Y Z$ crowns was even higher than the one of the zirconia implants and consequently, the implants fractured. The implants fractured at forces that were almost three times higher than the maximum chewing forces. Hence, the risk of an implant fracture in clinical use is low. However, the results indicate that the implant might be the weakest link when restored with a zirconia restoration.

The loading capacities of VE and CT were statistically similar, although the fracture load of CT was slightly but not statistically significant decreased after aging whereas VE remained stable. CT may be more sensitive to aging due to its higher polymeric content that absorbs water over time [32], which is probably also the cause of the decrease in flexural strength of CT after thermocyclic aging. However, as water absorption is a surface effect, no significant impact on the loading capacity of the CT crowns was observed. That might be explained by the higher volume-to-surface ratio of the crowns compared to the flexural strength specimens. VE also revealed a decrease in flexural strength after thermal cycling, probably due to the polymeric 
portion as well. However, the fracture load of VE was not affected by thermal cycling. The cement VAF that was applied for VE revealed a significantly higher compressive strength than RUL that was used for CT. For VE it is known that a high compressive strength of the resin composite cement can improve the fracture load values $[10,17]$. Thus, the higher compressive strength of VAF might have compensated the decrease in flexural strength of VE. Previous fracture load values [10] that were reported after $24 \mathrm{~h}$ water storage at $37^{\circ} \mathrm{C}$ for VE with VAF $(1297 \pm 150 \mathrm{~N})$ on zirconia implants were lower than those obtained in the present study $(1592 \pm 271 \mathrm{~N})$. The implant diameter of the zirconia implant in the previous study was $4.0 \mathrm{~mm}$, in the present $4.5 \mathrm{~mm}$ while the outer crown contour and test set-up was the same. The increased diameter of the abutment must have resulted in a better distribution of the loading force within the crown material. Further, the crowns in the present study were treated with primer and the cement was light-cured while the VE crowns of the previous study were cemented without primer and the cement was cured by autopolymerization [17]. Fractures of all-ceramic restorations in clinical use occur at considerably lower forces than observed in the present investigation [33]. It has to be acknowledged that crowns on one-piece zirconia implants display an increased wall thickness due to the small geometry of the abutment part. Thus, the load bearing capacity of these restorations is higher than that of ceramic restorations placed on individually designed abutments as applied for some restorations on titanium implants.

The fractures of the present study mainly initiated from the loading point due to the high force that was applied. Crown fractures in clinical situations may be caused by critical stress concentrations, cyclic fatigue (subcritical crack growth) or occur as a result of processing flaws or inadequate restoration design [34]. Consequently, crack initiation and crack propagation are more complex and usually induced by multiple 
fracture origins [35]. Features like compression curl, hackle, wake hackle, twist hackle, and arrest lines are commonly found markings in failed ceramic restorations [36-39]. For zirconia crowns on implants it has been observed that especially restorations with thin walls in the cervical region connecting the crown to the implant are vulnerable to contact damage [35].

The retention capacity of all crown materials that were fixed on the zirconia implants with resin composite cements were similar and not affected by the aging process. Concerns have been raised regarding the long-term bonding capability to zirconia [40] and polymer [41]. The results obtained in the present study indicate clearly that although shear bond strength values to both crown and implant varied significantly among the materials, they did not seem to substantially affect the crown retention. That the retention capacity of the crowns was neither affected by the material used nor the aging process must therefore be mainly due to the high strength and stability of the applied resin composite cements rather than their bonding capability. It has been proposed that a tight fit of the cement layer on the implant abutment and the intaglio surface of the crown results in a vacuum effect that has to be overcome in order to remove the crown [22]. In the literature, the retention capacity of only VE [22] and lithium disilicate [21] crowns on zirconia abutments has been evaluated using different cements. Lithium disilicate crowns cemented with RUN displayed a significant decrease in retention force after thermal cycling [21], which is in contrast to the present results where retention force of $\mathrm{YZ}$ crowns cemented with RUN was not affected by thermal cycling. It might be that a different fit of the crowns, and the resulting cement thickness influences the outcome. No significant difference has been reported regarding the retention capacity for VE crowns cemented with either one of the resin composite cements VAF, RUN or RUL irrespective if primer was applied or not [22]. 
The chewing simulation of 1.2 Mio cycles that was applied with a force of $49 \mathrm{~N}$ is reported to simulate aging in the mouth of 5 years $[18,42]$. In most studies where a chewing simulation is applied, steatite is used as an antagonist [20,24,26-28,42]. Steel was chosen in the present study to potentially increase the aging effect and simulate a worst-case situation. Despite the intensified stress the loading and retention capacity of the tested materials were not affected significantly by the aging procedure. Therefore, for future studies fracture load and retention values after $24 \mathrm{~h}$ are recommended by the authors to test basic material behavior. In addition, thermocyclic aging of the components may be further performed to estimate their aging potential. The specimens used for testing the mechanical properties of the materials reveal a more delicate shape with a higher surface/volume ratio than when they are tested as a crown-cement-implant system and are therefore more susceptible to aging protocols.

Chewing simulation of crowns can be used to visualize the abrasion potential of different materials, however, ball-on-disc wear simulations seem more adequate to estimate a materials' wear potential $[15,43,44]$ due to the increased control of the load application on the substrates topography. Additionally, ball-on disc wear simulations consider lateral load movements as they occur during chewing, thus evaluate abrasion more precisely than the performed chewing simulation. In the present study the aim was to include the effect of the topography of the occlusal surface and the differences in the complex elastic behavior of the whole system comprising implant, cement, and crown. Abrasion was higher for CT than for VE and YZ. Although there has been a tendency towards an increased abrasion for materials with low hardness values as also observed in the present study, the abrasion potential of a material does not correlate directly to their hardness $[15,43]$. The occlusal surface finish is important, especially for materials with ceramic content 
because abrasion tended to be higher for unpolished specimens of VE and $Y Z$ than for the polished ones. In a previous study the wear of enamel antagonists to machined, polished or glazed zirconia was analyzed. Glazed zirconia surfaces resulted in a significantly higher abrasion of the enamel antagonist than machined zirconia, which was also significantly higher than polished surfaces [44]. For VE, abrasion after chewing simulation has been previously analyzed using a microCT with similar results as in the present study [28]. Abrasion of VE is similar as for human enamel [43]. Material build-up around the abrasion as it was found for $Y Z$ and VE was due to wear of the steel antagonist for $Y Z$ and for $V E$ the material itself was found to be pushed to the rim of the abrasion area.

All tested material combinations in the present study have their advantages and disadvantages but seem all suitable for the restorative single crown treatment of zirconia implants in the molar region. Monolithic zirconia should be the material of choice in situations when esthetic demands are not in focus and easy handling of the cementation process is required. However, it has to be acknowledged that if overload occurs it is likely to affect the implant instead of the zirconia crown. Considering this aspect, the elastic crown materials with their lower strength may be more suitable. Polymer-infiltrated ceramic with an adhesive cement with high compressive strength is the material for any situation where an adequate cementation can be performed. Another option would be the use of polymer crowns with a cement providing the proper universal adhesive for a polymeric bond. However, no data is available on the long-term performance of CT crowns because the material is currently only approved for a temporary crown solution by the manufacturer.

The outcomes of a clinical study based on the present results, which is currently performed at the University of Zurich, will provide more information on a proper materials choice for the restorative treatment of zirconia implants. 


\section{CONCLUSION}

Within the limitations of this study it can be concluded that:

- All tested materials can be recommended for the use on zirconia implants, however polymer crowns are currently only approved for a temporary crown solution by the manufacturer.

- The loading and retention capacity of the tested materials are not affected significantly by aging with a chewing simulation.

- No correlation was observed between mechanical properties and loading or retention capacity of the respective materials. 


\section{REFERENCES}

[1] Osman R, Swain M. A critical review of dental implant materials with an emphasis on titanium versus zirconia. Materials 2015;8:932-58. https://doi.org/10.3390/ma8030932.

[2] Spies BC, Stampf S, Kohal RJ. Evaluation of zirconia-based all-ceramic single crowns and fixed dental prosthesis on zirconia implants: 5-year results of a prospective cohort study. Clin Implant Dent Relat Res 2015;17:1014-28. https://doi.org/10.1111/cid.12203.

[3] Hashim D, Cionca N, Courvoisier DS, Mombelli A. A systematic review of the clinical survival of zirconia implants. Clin Oral Investig 2016;20:1403-17. https://doi.org/10.1007/s00784-016-1853-9.

[4] Pieralli S, Kohal RJ, Jung RE, Vach K, Spies BC. Clinical outcomes of zirconia dental implants: a systematic review. J Dent Res 2017;96:38-46. https://doi.org/10.1177/0022034516664043.

[5] Spies BC, Kohal RJ, Balmer M, Vach K, Jung RE. Evaluation of zirconia-based posterior single crowns supported by zirconia implants: preliminary results of a prospective multicenter study. Clin Oral Implants Res 2017;28:613-9. https://doi.org/10.1111/clr.12842.

[6] Balmer M, Spies BC, Vach K, Kohal RJ, Hämmerle CHF, Jung RE. Three-year analysis of zirconia implants used for single-tooth replacement and three-unit fixed dental prostheses: A prospective multicenter study. Clin Oral Implants Res 2018;29:290-9. https://doi.org/10.1111/clr.13115.

[7] Piconi C, Maccauro G. Zirconia as a ceramic biomaterial. Biomaterials 1999;20:125. 
[8] Cordeiro JM, Beline T, Ribeiro ALR, Rangel EC, da Cruz NC, Landers R, et al. Development of binary and ternary titanium alloys for dental implants. Dent Mater 2017;33:1244-57. https://doi.org/10.1016/j.dental.2017.07.013.

[9] Spies BC, Balmer M, Jung RE, Sailer I, Vach K, Kohal RJ. All-ceramic, bi-layered crowns supported by zirconia implants: Three-year results of a prospective multicenter study. J Dent 2017;67:58-65. https://doi.org/10.1016/j.jdent.2017.09.008. [10] Rohr N, Märtin S, Fischer J. Correlations between fracture load of zirconia implant supported single crowns and mechanical properties of restorative material and cement. Dent Mater J 2018;37:222-8. https://doi.org/10.4012/dmj.2017-111.

[11] Zaugg LK, Meyer S, Rohr N, Zehnder I, Zitzmann NU. Fracture behavior, marginal gap width, and marginal quality of vented or pre-cemented CAD/CAM allceramic crowns luted on Y-TZP implants. Clin Oral Implants Res 2018;29:175-84. https://doi.org/10.1111/clr.13075.

[12] Weyhrauch M, Igiel C, Scheller H, Weibrich G, Lehmann KM. Fracture Strength of Monolithic All-Ceramic Crowns on Titanium Implant Abutments. Int $\mathrm{J}$ Oral Maxillofac Implants 2016;31:304-9. https://doi.org/10.11607/jomi.4601.

[13] Stawarczyk B, Beuer F, Ender A, Roos M, Edelhoff D, Wimmer T. Influence of cementation and cement type on the fracture load testing methodology of anterior crowns made of different materials. Dent Mater J 2013;32:888-95. https://doi.org/10.4012/dmj.2013-147.

[14] Nakamura K, Mouhat M, Nergård JM, Lægreid SJ, Kanno T, Milleding P, et al. Effect of cements on fracture resistance of monolithic zirconia crowns. Acta Biomater Odontol Scand 2016;2:12-9. https://doi.org/10.3109/23337931.2015.1129908.

[15] Lawson NC, Bansal R, Burgess JO. Wear, strength, modulus and hardness of CAD/CAM restorative materials. Dent Mater 2016;32:e275-e83. https://doi.org/10.1016/j.dental.2016.08.222. 
[16] Spies BC, Pieralli S, Vach K, Kohal RJ. CAD/CAM-fabricated ceramic implantsupported single crowns made from lithium disilicate: Final results of a 5-year prospective cohort study. Clin Implant Dent Relat Res 2017;19:876-83. https://doi.org/10.1111/cid.12508.

[17] Rohr N, Coldea A, Zitzmann NU, Fischer J. Loading capacity of zirconia implant supported hybrid ceramic crowns. Dent Mater 2015;31:e279-e88. https://doi.org/10.1016/j.dental.2015.09.012.

[18] Kohal RJ, Kilian JB, Stampf S, Spies BC. All-ceramic single crown restauration of zirconia oral implants and its influence on fracture resistance: An investigation in the artificial mouth. Materials 2015;8:1577-89. https://doi.org/10.3390/ma8041577.

[19] Rosentritt M, Raab P, Hahnel S, Stöckle M, Preis V. In-vitro performance of CAD/CAM-fabricated implant-supported temporary crowns. Clin Oral Investig 2017;21:2581-7. https://doi.org/10.1007/s00784-017-2057-7.

[20] Sieper K, Wille S, Kern M. Fracture strength of lithium disilicate crowns compared to polymer-infiltrated ceramic-network and zirconia reinforced lithium silicate crowns. J Mech Behav Biomed Mater 2017;74:342-8. https://doi.org/10.1016/j.jmbbm.2017.06.025.

[21] Sellers K, Powers JM, Kiat-Amnuay S. Retentive strength of implant-supported CAD-CAM lithium disilicate crowns on zirconia custom abutments using 6 different $\begin{array}{llll}\text { cements. } & \text { J } & \text { Prosthet } & \text { 2017; } 117: 247-52 \text {. }\end{array}$ https://doi.org/10.1016/j.prosdent.2016.06.014.

[22] Rohr N, Brunner S, Märtin S, Fischer J. Influence of cement type and ceramic primer on retention of polymer-infiltrated ceramic crowns to a one-piece zirconia $\begin{array}{llll}\text { implant. J Prosthet 2018;119:138-45. } & \text { J Dent }\end{array}$ https://doi.org/10.1016/j.prosdent.2017.02.002. 
[23] Dogan DO, Gorler O, Mutaf B, Ozcan M, Eyuboglu GB, Ulgey M. Fracture resistance of molar crowns fabricated with monolithic all-ceramic cad/cam materials cemented on titanium abutments: an in vitro study. J Prosthodont 2017;26:309-14. https://doi.org/10.1111/jopr.12393.

[24] Mitsias M, Koutayas SO, Wolfart S, Kern M. Influence of zirconia abutment preparation on the fracture strength of single implant lithium disilicate crowns after chewing simulation. Clin Oral Implants Res 2014;25:675-82. https://doi.org/10.1111/clr.12058.

[25] Rohr N, Flury A, Fischer J. Efficacy of a universal adhesive in the bond strength of composite cements to polymer-infiltrated ceramic. J Adhes Dent 2017;19:417-24. https://doi.org/10.3290/j.jad.a39277.

[26] Preis V, Hahnel S, Behr M, Bein L, Rosentritt M. In-vitro fatigue and fracture testing of CAD/CAM-materials in implant-supported molar crowns. Dent Mater 2017;33:427-33. https://doi.org/10.1016/j.dental.2017.01.003.

[27] Rosentritt M, Hahnel S, Engelhardt F, Behr M, Preis V. In vitro performance and fracture resistance of CAD/CAM-fabricated implant supported molar crowns. Clin Oral Investig 2017;21:1213-9. https://doi.org/10.1007/s00784-017-2057-7.

[28] Baumgart P, Kirsten H, Haak R, Olms C. Biomechanical properties of polymerinfiltrated ceramic crowns on one-piece zirconia implants after long-term chewing simulation. Int J Implant Dent 2018;4:16. https://doi.org/10.1186/s40729-018-0127-5. [29] Shinogaya T, Bakke M, Thomsen CE, Vilmann A, Matsumoto M. Bite force and occlusal load in healthy young subjects--a methodological study. Eur J Prosthodont Restor Dent 2000;8:11-5.

[30] Peck CC. Biomechanics of occlusion - implications for oral rehabilitation. J Oral Rehabil 2016;43:205-14. https://doi.org/10.1111/joor.12345. 
[31] Fontijn-Tekamp FA, Slagter AP, Van Der Bilt A, Van 'T Hof MA, Witter DJ, Kalk $\mathrm{W}$, et al. Biting and chewing in overdentures, full dentures, and natural dentitions. J Dent Res 2000;79:1519-24. https://doi.org/10.1177/00220345000790071501.

[32] Liebermann A, Wimmer T, Schmidlin PR, Scherer H, Löffler P, Roos M, et al. Physicomechanical characterization of polyetheretherketone and current esthetic dental CAD/CAM polymers after aging in different storage media. J Prosthet Dent 2016;115:321-8. https://doi.org/10.1016/j.prosdent.2015.09.004.

[33] Øilo M, Kvam K, Gjerdet NR. Simulation of clinical fractures for three different allceramic crowns. Eur J Oral Sci 2014;122:245-50. https://doi.org/10.1111/eos.12128. [34] Scherrer SS, Lohbauer U, Della Bona A, Vichi A, Tholey MJ, Kelly JR, van Noort R, Cesar PF. ADM guidance-Ceramics: guidance to the use of fractography in failure analysis of brittle materials. Dent Mater 2017;33:599-620. https://doi.org/10.1016/j.dental.2017.03.004.

[35] Øilo M, Arola D. Fractographic analyses of failed one-piece zirconia implant restorations. Dent Mater 2018;34:922-931. https://doi.org/10.1016/j.dental.2018.03.018.

[36] Quinn JB, Quinn GD, Kelly JR, Scherrer SS. Fractographic analyses of three ceramic whole crown restoration failures. Dent Mater 2005;21:920-9. https://doi.org/10.1016/j.dental.2005.01.006.

[37] Scherrer SS, Quinn JB, Quinn GD, Kelly JR. Failure analysis of ceramic clinical cases using qualitative fractography. Int J Prosthodont. 2006;19:185-92.

[38] Scherrer SS, Quinn JB, Quinn GD, Wiskott HW. Fractographic ceramic failure analysis using the replica technique. Dent Mater 2007;23:1397-404. https://doi.org/10.1016/j.dental.2006.12.002. 
[39] Lohbauer U, Amberger G, Quinn GD, Scherrer SS. Fractographic analysis of a dental zirconia framework: a case study on design issues. J Mech Behav Biomed Mater 2010;3:623-9. https://doi.org/10.1016/j.jmbbm.2010.07.004.

[40] Bömicke W, Schürz A, Krisam J, Rammelsberg P, Rues S. Durability of ResinZirconia Bonds Produced Using Methods Available in Dental Practice. J Adhes Dent 2016;18:17-27. https://doi.org/10.3290/j.jad.a35517.

[41] Keul C, Kohen D, Eichberger M, Roos M, Gernet W, Stawarczyk B. The effect of different pretreatment methods of PMMA-based crowns on the long-term tensile bond strength to dentin abutments. Clin Oral Investig 2015;19:35-43. https://doi.org/10.1007/s00784-014-1215-4.

[42] Kohal RJ, Finke HC, Klaus G. Stability of prototype two-piece zirconia and titanium implants after artificial aging: an in vitro pilot study. Clin Implant Dent Relat Res 2009;11:323-9. https://doi.org/10.1111/j.1708-8208.2008.00116.x.

[43] Hao Z, Ma Y, Liu W, Meng Y, Nakamura K, Shen J, et al. Influence of lowtemperature degradation on the wear characteristics of zirconia against polymerinfiltrated ceramic-network material. J Prosthet Dent 2018;120:596-602. https://doi.org/10.1016/j.prosdent.2017.12.014.

[44] Lawson NC, Janyavula S, Syklawer S, McLaren EA, Burgess JO. Wear of enamel opposing zirconia and lithium disilicate after adjustment, polishing and glazing. J Dent 2014;42:1586-91. https://doi.org/10.1016/j.jdent.2014.09.008. 


\section{TABLES AND FIGURES}

TABLE 1 - Restorative and cement materials used.

TABLE 2 - Pretreatment of the respective materials.

TABLE 3 - Means and standard deviations of the abrasion volume (V) and the abrasion depth (d) at the occlusal surface of the either polished or unpolished crowns of $Y Z$, VE and CT.

TABLE 4 - Means and standard deviations of the mechanical properties of restorative and cement materials and bonding properties between restorative materials and cements as well as between implant and cements. Statistical similar groups obtained with the post-hoc test are marked with superscript letters within one property group, for vertical comparison uppercase, horizontal comparison lower case letters.

FIG. 1 - Testing diagram for the restorative treatment options on the zirconia implant and table of the parameters that were tested separately for the respective materials.

FIG. 2 - Loading capacity and crown retention means and standard deviation after 1d water storage at $37^{\circ} \mathrm{C}$ (Baseline) and after chewing simulation followed by thermocyclic aging (Aging).

FIG. 3 - Light microscopic images of gold-coated fractured crowns of YZ, VE and CT. Arrows indicate fracture paths.

FIG. 4 - Abrasion images of unpolished crowns of YZ, VE and CT after aging in the chewing simulator given by matching STL data with the software Oracheck. 


\begin{tabular}{|c|c|c|c|c|c|}
\hline Material & Type & Name & Code & Lot-Nr. & Manufacturer \\
\hline \multirow{3}{*}{ Restorative } & Zirconia & Vita YZ T & $\mathrm{YZ}$ & 57161 & \multirow{3}{*}{$\begin{array}{l}\text { Vita Zahnfabrik } \\
\text { Bad Säckingen } \\
\text { Germany }\end{array}$} \\
\hline & $\begin{array}{l}\text { Polymer-infiltrated } \\
\text { ceramic }\end{array}$ & Vita Enamic & VE & 45360 & \\
\hline & Acrylate polymer & Vita CAD-Temp & CT & 28440 & \\
\hline \multirow{3}{*}{ Cement } & $\begin{array}{l}\text { Self-adhesive resin } \\
\text { composite }\end{array}$ & $\begin{array}{l}\text { RelyX Unicem } 2 \\
\text { Automix }\end{array}$ & RUN & 607206 & $\begin{array}{l}\text { 3M Espe } \\
\text { Seefeld } \\
\text { Germany }\end{array}$ \\
\hline & \multirow{2}{*}{$\begin{array}{l}\text { Adhesive resin } \\
\text { composite }\end{array}$} & Vita Adiva F-Cem & VAF & 71702177 & $\begin{array}{l}\text { Vita Zahnfabrik } \\
\text { Bad Säckingen } \\
\text { Germany }\end{array}$ \\
\hline & & RelyX Ultimate & RUL & 657610 & $\begin{array}{l}\text { 3M Espe } \\
\text { Seefeld } \\
\text { Germany }\end{array}$ \\
\hline
\end{tabular}

TABLE 1 - Restorative and cement materials used. 


\begin{tabular}{|c|c|c|c|}
\hline Restorative material & Zirconia (YZ) & $\begin{array}{c}\text { Polymer-infiltrated ceramic } \\
\text { (VE) }\end{array}$ & Acrylate polymer (CT) \\
\hline \multirow{3}{*}{$\begin{array}{l}\text { Pretreatment } \\
\text { Crown }\end{array}$} & $\begin{array}{l}\text { Sandblasting } \mathrm{Al}_{2} \mathrm{O}_{3} 50 \mu \mathrm{m} \\
\text { with } 2 \text { bar }\end{array}$ & $\begin{array}{l}\text { Ultrasonic cleaning with } 70 \% \\
\text { ethanol for } 4 \mathrm{~min}\end{array}$ & $\begin{array}{l}\text { Sandblasting } \mathrm{Al}_{2} \mathrm{O}_{3} 50 \mu \mathrm{m} \\
\text { with } 2 \text { bar }\end{array}$ \\
\hline & $\begin{array}{l}\text { Ultrasonic cleaning with } \\
70 \% \text { ethanol for } 4 \mathrm{~min}\end{array}$ & HF $5 \%$ etching for 60 s & $\begin{array}{l}\text { Ultrasonic cleaning with } 70 \% \\
\text { ethanol for } 4 \mathrm{~min}\end{array}$ \\
\hline & - & Silane (Vitasil) for 60s & $\begin{array}{l}\text { Primer (Scotchbond } \\
\text { Universal Adhesive) for } 20 \text { s }\end{array}$ \\
\hline Cement & $\begin{array}{l}\text { Self-adhesive resin } \\
\text { composite (RUN) }\end{array}$ & $\begin{array}{l}\text { Adhesive resin } \\
\text { composite (VAF) }\end{array}$ & $\begin{array}{c}\text { Adhesive resin } \\
\text { composite (RUL) }\end{array}$ \\
\hline \multirow{2}{*}{$\begin{array}{l}\text { Pretreatment } \\
\text { Abutment }\end{array}$} & \multicolumn{3}{|c|}{ Ultrasonic cleaning with $70 \%$ ethanol for $4 \mathrm{~min}$} \\
\hline & - & $\begin{array}{l}\text { Primer (Vita Adiva ZR- } \\
\text { Prime) for 10s }\end{array}$ & $\begin{array}{l}\text { Primer (Scotchbond } \\
\text { Universal Adhesive) for 20s }\end{array}$ \\
\hline Implant abutment & \multicolumn{3}{|c|}{ Zirconia (ceramic.implant) } \\
\hline
\end{tabular}

TABLE 2 - Pretreatment of the respective materials. 


\begin{tabular}{l|c|c|c|c|c|c}
\hline & \multicolumn{2}{|c|}{ YZ } & \multicolumn{2}{c|}{ VE } & \multicolumn{2}{c}{ CT } \\
& polished & unpolished & polished & unpolished & polished & unpolished \\
\hline $\mathbf{V}\left(\mathrm{mm}^{3}\right)$ & $0.01 \pm 0.01$ & $0.02 \pm 0.03$ & $0.02 \pm 0.05$ & $0.07 \pm 0.07$ & $0.14 \pm 0.09$ & $0.13 \pm 0.11$ \\
\hline $\mathbf{d}(\mu \mathrm{m})$ & $11.2 \pm 2.1$ & $28.6 \pm 18.2$ & $33.7 \pm 17.6$ & $64.6 \pm 33.8$ & $128.5 \pm 34.7$ & $130.7 \pm 48.2$ \\
\hline
\end{tabular}

TABLE 3 - Means and standard deviation of the abrasion volume (V) and the abrasion depth (d) at the occlusal surface of the either polished or unpolished crowns of YZ, VE and CT. 
Baseline

$24 \mathrm{~h}$ water storage $37^{\circ} \mathrm{C}$
Aging

24h water storage $37^{\circ} \mathrm{C}+$ 20 '000 thermal cycles

\begin{tabular}{|c|c|c|}
\hline \multirow[b]{3}{*}{ YZ } & \multicolumn{2}{|c|}{ Restorative materials } \\
\hline & \multicolumn{2}{|c|}{ Flexural strength (MPa) } \\
\hline & $988.5 \pm 115.3^{\mathrm{A}, \mathrm{a}}$ & $978.3 \pm 93.1^{\mathrm{A}, \mathrm{a}}$ \\
\hline VE & $132.7 \pm 17.0^{\mathrm{B}, \mathrm{a}}$ & $114.2 \pm 6.3^{\mathrm{B}, \mathrm{b}}$ \\
\hline \multirow[t]{2}{*}{ CT } & $100.4 \pm 3.6^{\mathrm{C}, \mathrm{a}}$ & $88.7 \pm 3.9^{\mathrm{C}, \mathrm{b}}$ \\
\hline & \multicolumn{2}{|c|}{ Fracture toughness $(\mathrm{MPa} \vee \mathrm{m})$} \\
\hline YZ & $6.20 \pm 1.22^{\mathrm{A}, \mathrm{a}}$ & $5.11 \pm 0.49^{A, b}$ \\
\hline VE & $1.82 \pm 0.29^{\mathrm{B}, \mathrm{a}}$ & $1.19 \pm 0.02^{\mathrm{B}, \mathrm{b}}$ \\
\hline \multirow[t]{2}{*}{ CT } & $1.72 \pm 0.28^{\mathrm{C}, \mathrm{a}}$ & $1.05 \pm 0.02^{\mathrm{C}, \mathrm{a}}$ \\
\hline & \multicolumn{2}{|c|}{ Vickers Hardness (HV1) } \\
\hline YZ & $1553.3 \pm 88.5^{\mathrm{A}, \mathrm{a}}$ & $1625.7 \pm 23.0^{A, b}$ \\
\hline VE & $151.9 \pm 2.4^{\mathrm{B}, \mathrm{a}}$ & $272.8 \pm 21.5^{\mathrm{B}, \mathrm{b}}$ \\
\hline \multirow[t]{2}{*}{ CT } & $30.3 \pm 1.1^{\mathrm{c}, \mathrm{a}}$ & $33.7 \pm 2.6^{\mathrm{C}, \mathrm{a}}$ \\
\hline & \multicolumn{2}{|c|}{ Martens Hardness $\left(\mathrm{N} / \mathrm{mm}^{2}\right)$} \\
\hline YZ & $7537.4 \pm 604.3^{\mathrm{A}, \mathrm{a}}$ & $5713.2 \pm 818.0^{\mathrm{A}, \mathrm{b}}$ \\
\hline VE & $1019.2 \pm 113.8^{\mathrm{B}, \mathrm{a}}$ & $1059.0 \pm 230.7^{\mathrm{B}, \mathrm{a}}$ \\
\hline \multirow[t]{3}{*}{ CT } & $151.1 \pm 7.7^{\mathrm{C}, \mathrm{a}}$ & $165.8 \pm 8.6^{\mathrm{C}, \mathrm{a}}$ \\
\hline & \multicolumn{2}{|c|}{ Cement materials } \\
\hline & \multicolumn{2}{|c|}{ Compressive strength (MPa) } \\
\hline RUN & $283.2 \pm 17.3^{\mathrm{A}, \mathrm{a}}$ & $273.1 \pm 28.2^{\mathrm{A}, \mathrm{a}}$ \\
\hline VAF & $385.4 \pm 22.5^{\mathrm{B}, \mathrm{a}}$ & $389.8 \pm 15.1^{\mathrm{B}, \mathrm{a}}$ \\
\hline \multirow[t]{3}{*}{ RUL } & $293.5 \pm 10.5^{\mathrm{A}, \mathrm{a}}$ & $286.6 \pm 14.5^{\mathrm{A}, \mathrm{a}}$ \\
\hline & \multicolumn{2}{|c|}{ Bonding properties } \\
\hline & \multicolumn{2}{|c|}{ Shear bond strength (MPa) } \\
\hline YZ/RUN & $3.3 \pm 3.7^{\mathrm{A}, \mathrm{a}}$ & $2.4 \pm 4.0^{\mathrm{A}, \mathrm{a}}$ \\
\hline VE/VAF & $9.9 \pm 0.6^{\mathrm{B}, \mathrm{a}}$ & $10.0 \pm 1.2^{\mathrm{B}, \mathrm{a}}$ \\
\hline \multirow[t]{2}{*}{$\mathrm{CT} / \mathrm{RUL}$} & $22.8 \pm 2.0^{\mathrm{C}, \mathrm{a}}$ & $20.4 \pm 2.4^{\mathrm{C}, \mathrm{a}}$ \\
\hline & \multicolumn{2}{|c|}{ Shear bond strength $(\mathrm{MPa})$} \\
\hline Impl/RUN & $0.0 \pm 0.0^{\mathrm{A}, \mathrm{a}}$ & $0.0 \pm 0.0^{\mathrm{A}, \mathrm{a}}$ \\
\hline Impl/VAF & $3.8 \pm 0.9^{\mathrm{B}, \mathrm{a}}$ & $0.0 \pm 0.0^{A, b}$ \\
\hline Impl/RUL & $13.2 \pm 2.9^{\mathrm{C}, \mathrm{a}}$ & $8.8 \pm 1.4^{\mathrm{B}, \mathrm{b}}$ \\
\hline
\end{tabular}

TABLE 4 - Means and standard deviations of the mechanical properties of restorative and cement materials and bonding properties between restorative materials and cements as well as between implant and cements. Statistical similar groups obtained with the post-hoc test are marked with superscript letters within one property group, for vertical comparison uppercase, horizontal comparison lower case letters. 
FIG. 1 - Testing diagram for the restorative treatment options on the zirconia implant and table of the parameters that were tested separately for the respective materials.
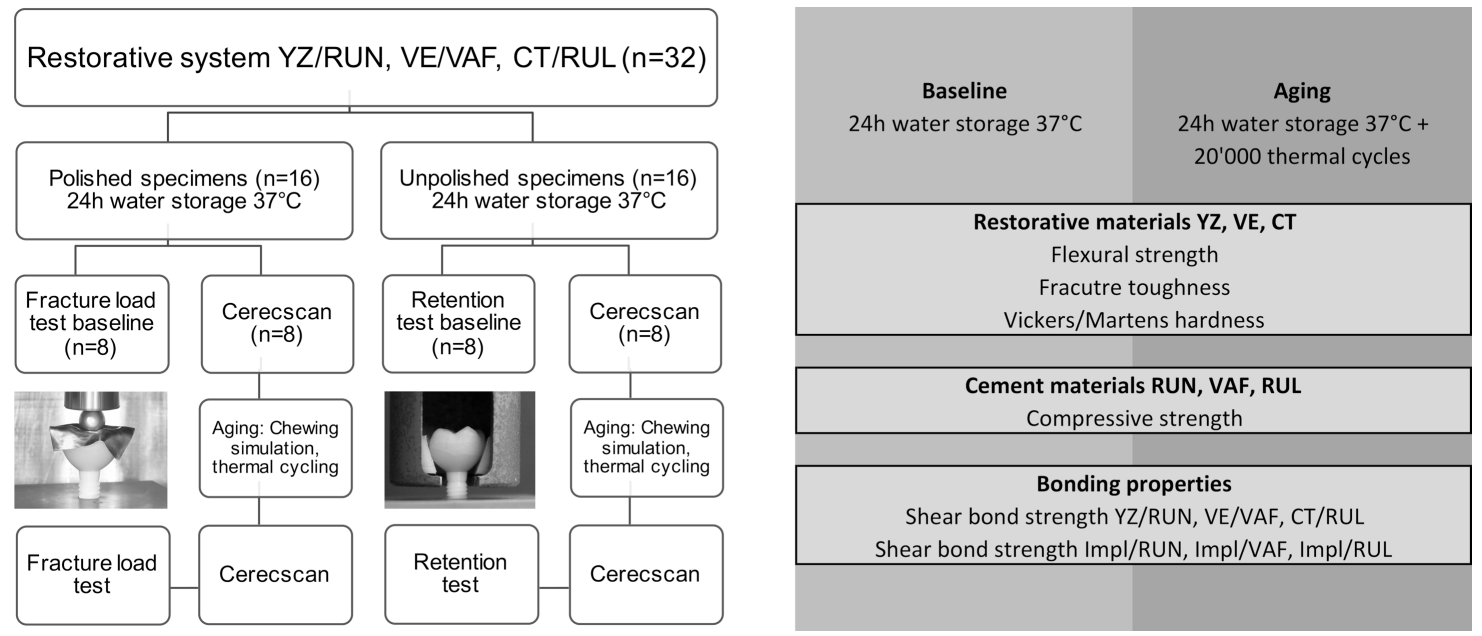
FIG. 2 - Loading capacity and crown retention means and standard deviation after 1d water storage at $37^{\circ} \mathrm{C}$ (Baseline) and after chewing simulation followed by thermocyclic aging (Aging).

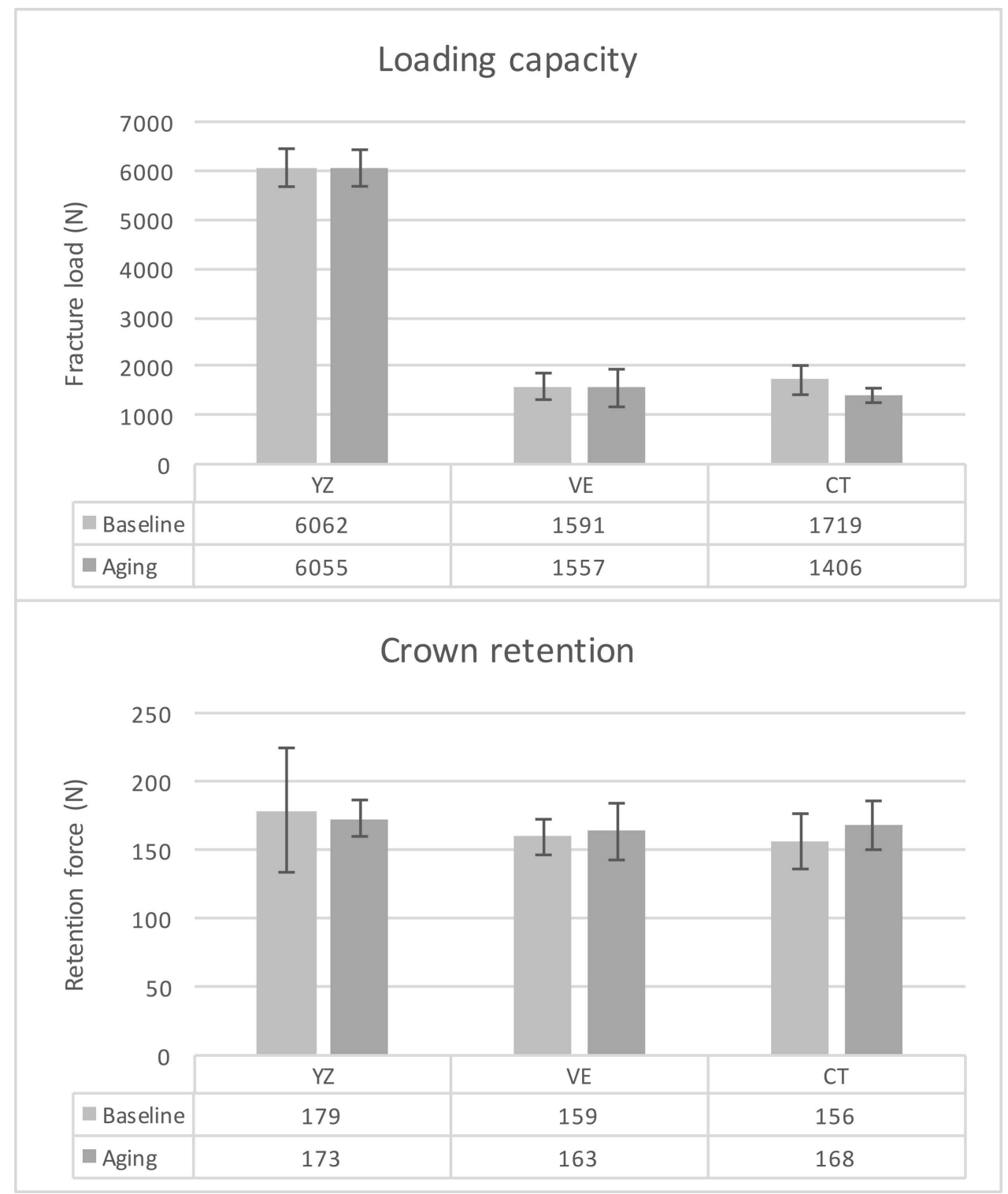


FIG. 3 - Light microscopic images of gold-coated fractured crowns of YZ, VE and CT. Arrows indicate fracture paths.

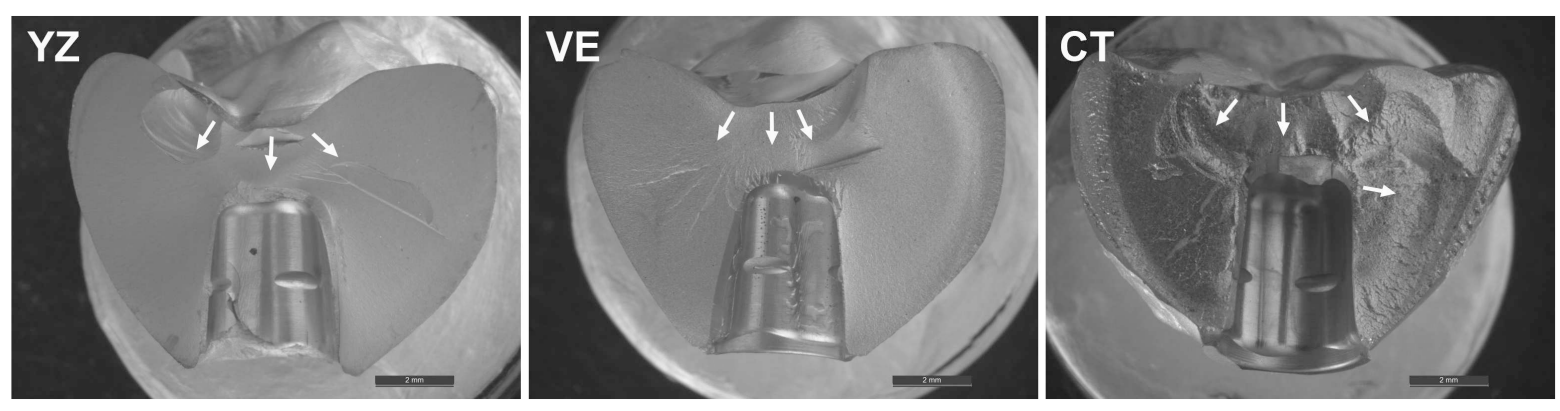


FIG. 4 - Abrasion images of unpolished crowns of YZ, VE and CT after aging in the chewing simulator given by matching STL data with the software Oracheck.
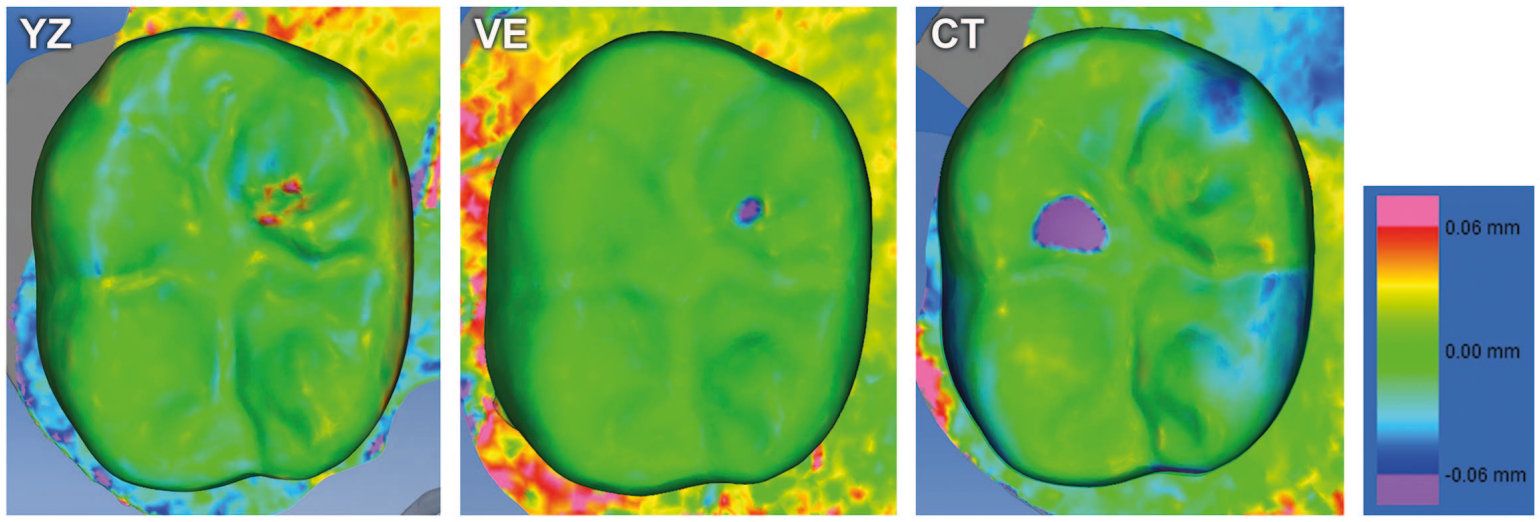